\title{
INFORMAÇÃO COLORIMÉTRICA DE MORANGOS REVESTIDOS COM AMIDO MODIFICADO
}

\author{
Aline Inacio Alves ${ }^{1}$ \\ Danielle Inacio Alves ${ }^{2}$ \\ Samuel de Assis Silva ${ }^{3}$ \\ Sergio Henriques Saraiva ${ }^{4}$
}

Resumo: Com este trabalho se objetivou utilizar o processamento digital de imagens para avaliar, ao longo do tempo de armazenamento, a qualidade de morangos revestidos com amido modificado. O experimento foi desenvolvido na Universidade Federal do Espírito Santo. Amostras de morango foram imersas em revestimento à base de amido, sendo o grupo controle (sem revestimento) imerso em água destilada estéril, nas mesmas condições. Os morangos foram avaliados quanto à reflectância nos comprimentos de onda do espectro eletromagnético do visível (400 a 700nm), através do processamento digital de imagens. Foram obtidas imagens em três épocas distintas ao longo do período de armazenamento dos morangos. $O$ delineamento estatístico utilizado foi o inteiramente casualizado com quatro repetições. $A$ utilização de técnicas de processamento digital de imagens foi eficiente para estudar o comportamento de morangos durante o período de armazenamento. O biofilme comestível à base de amido modificado apresentou melhores resultados que a testemunha, retardando o apodrecimento dos morangos e mantendo, por mais tempo, a qualidade dos frutos.

Palavras-chave: Engenharia de alimentos, processamento digital de imagens, frutas, biofilmes.

\footnotetext{
1 Universidade Federal de Viçosa, Brasil. E-mail: aline_inacio27@hotmail.com.

2 Universidade Federal do Espírito Santo, Brasil. E-mail: danielle.inacio@hotmail.com.

3 Universidade Federal do Espírito Santo, Brasil. E-mail: sasilva@pq.cnpq.br.

4 Universidade Federal do Espírito Santo, Brasil. E-mail: sergiohsaraiva@gmail.com.
} 